\title{
РАЗРАБОТКА НАИЛУЧШИХ ДОСТУПНЫХ ТЕХНОЛОГИЙ С ЦЕЛЬЮ МАКСИМАЛЬНОГО СНИЖЕНИЯ ЗАГРЯЗНЯЮЩИХ ВЕЩЕСТВ В ОТХОДЯЩИХ ГАЗАХ
}

\section{DEVELOPING THE BEST AVAILABLE TECHNOLOGIES FOR THE PURPOSE OF REDUCING POLLUTANTS IN EXHAUST GASES}

M. Shklyar

K. Altynov

A. Azarov

N. Zhukova

Summary. This paper provides recommendations for the development and implementation of the best available technologies (BAT) in order to minimize the amount of pollutant emissions into the air. The recommendations were developed taking into account the experience of the survey, development and implementation of measures to reduce emissions of pollutants at asphalt concrete plants in the Volgograd region and are aimed at providing methodological assistance to employees of enterprises and designers in the development and implementation of the best available technologies. The expediency of introducing BAT is shown. The necessity of forming an approach to the development of BAT, in the field of organizing dedusting of construction industries, is substantiated on the basis of an analysis of the results of a survey of existing aspiration systems.

Keywords: best available technologies, aspiration, construction, technological processes, environment, dedusting, environmental safety, dust.

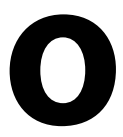
снову законодательства в области наилучших доступных технологий (НДТ) сформировал Федеральный закон от 21 июля 2014 г. N219-Ф3 «О внесении изменений в Федеральный закон «Об охране окружающей среды» и отдельные законодательные акты Российской Федерации», который совершенствует систему нормирования в области охраны окружающей среды, вводит в российское правовое поле понятие «наилучшая доступная технология» и меры экономического стимулирования хозяйствующих субъектов для внедрения НДТ.[1] Разработка и внедрение наилучших доступных технологий должна производится на основе современных достижений науки и техники и наилучше-

\author{
Шкляр Марина Александровна \\ Начальник отдела, ООО «ЭкоЦентр» \\ marishkl@mail.ru \\ Алтынов Константин Сергеевич \\ Волгоградский государственный технический \\ университет \\ altynov_90@mail.ru \\ Азаров Артем Викторович \\ К.т.н., Волгоградский государственный технический \\ университет \\ artazarov@mail.ru \\ Жукова Наталья Сергеевна \\ К.т.н., доцент, Волгоградский государственный \\ технический университет \\ pns15@yandex.ru
}

Аннотация. В настоящей работе приведены рекомендации по разработке и внедрению наилучших доступных технологий (НДТ) с целью максимального снижения количества выбросов загрязняющих веществ в атмосферный воздух. Рекомендации разработаны с учетом опыта обследования, выработки и внедрения мероприятий по снижению выбросов загрязняющих веществ на асфальтобетонных предприятиях Волгоградской области и направлены на оказание методической помощи работникам предприятий и проектировщиков при разработке и внедрении наилучших доступных технологий. Показана целесообразность внедрения НДТ. Обосновывается необходимость формирования подхода к разработке НДТ, в области организации обеспыливания строительных производств, на основе анализа результатов обследования существующих систем аспирации.

Ключевые слова: наилучшие доступные технологии, аспирация, строительство, технологические процессы, окружающая среда, обеспыливание, экологическая безопасность, пыль.

го сочетания критериев с целью снижения негативного воздействия на окружающую среду.

В качестве стимулирования хозяйствующих субъектов рассматривается снижение или даже освобождение от взимания платы за негативное воздействие после внедрения наилучших доступных технологий (применение нулевого понижающего коэффициента).

В целях стимулирования юридических лиц и индивидуальных предпринимателей, осуществляющих хозяйственную и (или) иную деятельность, к проведению мероприятий по снижению негативного воздей- 
ствия на окружающую среду и внедрению наилучших доступных технологий при исчислении платы за негативное воздействие на окружающую среду к ставкам такой платы применяются следующие коэффициенты:«0» - за объем или массу выбросов загрязняющих веществ, сбросов загрязняющих веществ в пределах технологических нормативов после внедрения наилучших доступных технологий на объекте, оказывающем негативное воздействие на окружающую среду; «1» -за объем или массу выбросов загрязняющих веществ, сбросов загрязняющих веществ в пределах нормативов допустимых выбросов, нормативов допустимых сбросов. [2]

Планомерный переход на новую систему экологического регулирования, основанную на принципах наилучших доступных технологий (НДТ) запланирован на 2019-2025 годы.

В 2016 году бюро НДТ Федерального агентства по техническому регулированию и метрологии был разработан информационно-технический справочник по наилучшим доступным технологиям «Очистка выбросов вредных (загрязняющих) веществ в атмосферный воздух при производстве продукции (товаров), а также при проведении работ и оказании услуг на крупных предприятиях». [3]

НДТ 2-5 определяет максимально возможное извлечение из отходящих газов загрязняющих веществ и их последующее использование. Данная НДТ включает, в зависимости от конкретных условий, следующие подходы:

а) максимальное извлечение из отходящих газов содержащихся в них веществ, представляющих собой потери сырья или продукции, попутные продукты сжигания топлива и продукты газоочистки;

б) подготовка к утилизации с достижением максимальных потребительских свойств веществ, выделенных из отходящих газов в процессе очистки.

Данные подходы подлежат применению на действующих, модернизируемых и новых объектах.

Рассмотрим разработку наилучших доступных технологий на асфальтобетонных предприятиях. Основными источниками пылеобразования на асфальтобетонных предприятиях является оборудование, в котором осуществляется перемещение и перемешивание горячих материалов, и их соприкосновение с холодными материалами и средами. Это сушильный барабан, грохот, смеситель. В процессе приготовления асфальтобетонной смеси в данном оборудовании при соприкосновении горячих песка и щебня с холодной средой происходит интенсивное паровыделение, которое за счет давления в закрытом кожухе корпуса с силой вырывается из неплотностей, унося большое количество мелких частиц в окружающую среду.

Основными методами борьбы с данными пылевыделениями являются: уплотнение очагов пылеобразования кожухами с прокладками; отсос от всех очагов пылеобразования газов с целью создания разряжения.

Еще одной группой источников пылеобразования являются желоба, трубы, элеваторы-оборудование, которое своим движением создает эжектирующее действие потоков воздуха, способствующее уносу мельчайших частиц пыли, основным мероприятием по снижению пылевыделения от данного оборудования является его герметизация.

Одним из основных направлений деятельности по снижению выбросов в атмосферу от оборудования асфальтобетонных предприятий является повышение эффективности работы установок очистки газа.

Анализ результатов обследований асфальтобетонных предприятий, проведенных с учетом вышеизложенных направлений, позволил разработать ряд НДТ, направленных на снижение выбросов загрязняющих веществ в атмосферу.

На ряде асфальтобетонных предприятий Волгоградской области для очистки удаляемого из сушильного барабана газа используется в качестве первой ступени очистки прямоточный осевой циклон. При удалении подсосов в месте выгрузки уловленного продукта, данный циклон обеспечивает проектную эффективность очистки в 30-40\%. Однако общий эффект его работы незначителен, потому что уловленная им пыль возвращается в сушильный барабан в месте загрузки сырого поступающего на сушку материала. Так как уловленная пыль представляет собой сухой продукт, то она подхватывается выделяющимися парами от вновь загружаемого в сушильный барабан материала и повторно уносится системой аспирации.

В ходе эксперимента, когда прямоточный циклон был исключен из схемы (была перекрыта выгрузка уловленной пыли) концентрация пыли, поступающей на вторую ступень очистки возросла с 52 г/м3 до 55 г/м3, т.е. фактический вклад первой ступени в очистку удаляемого от сушильного барабана газа составил-5,8\% вместо проектных 30-40\%.

Направив уловленную прямоточным циклоном пыль вместо сушильного барабана в промежуточный бункер, 
с последующей подачей в горячий элеватор, получен следующий результат:

- при концентрации пыли в отходящих от сушиль-

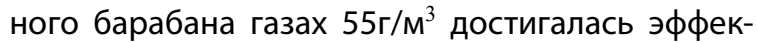
тивность очистки в прямоточном циклоне $30 \%$;

- на вторую ступень очистки поступали газы с концентрацией пыли-39г/м³.

Таким образом, изменение схемы выгрузки уловленной прямоточным циклоном пыли позволяет повысить его эффективность до проектной, снизив концентрацию пыли в поступающих на II ступень очистки газах на 25\%.

Экспериментальные исследования эффективности работы моделей инерционных пылеуловителей, применяемых по настоящее время на асфальтобетонных производствах УЦ, ЦН и пылеуловителей серии ВИЛ, показали преимущество пылеуловителей, работающих на встречных закрученных потоках. Эффективность очистки у них была на 10-15\% выше.

Внедрение промышленного образца пылеуловителей серии ВИП-600 на ряде предприятий Волгоградской области показало его высокую эффективность работы при очистке газов от пыли песка и щебня до 92\%.

Разработан номенклатурный ряд типоразмеров пылеуловителей на расход очищаемого газа 500016000 м3/ч.

Замена циклонов ЦН-15, СДКЦН-33, СЦН-40 на пылеуловители серии ВИЛ позволяет повысить эффективность очистки газов на $10-15 \%$.

В ходе обследований установлено, что на большинстве асфальтобетонных предприятий эффективность очистки в циклонах систем аспирации на 10-15\% ниже проектной. Причиной являются большие подсосы в месте выгрузки уловленной пыли до10\%.

С целью повышения эффективности работы систем предлагается в местах выгрузки проводит следующие модернизации:

- установить патрубки из оргстекла для своевременного принятия мер в случае образования свода пыли;

- установить предохранительную питающую воронку в верхнем приёмном патрубке шлюзового питателя для устранения завалов;

- установить по краям лопаток шлюзового питателя резиновые пластины, препятствующие подсосам воздуха в пылеуловитель через шлюзовой питатель.

Внедрение данных мероприятий позволяет снизить величину подсосов до $1 \%$ и повысить эффективность очистки в циклонах СДКЦН, СЦН и ЦН до паспортных величин.

На ряде предприятий Волгоградской области в системах аспирации применяются дымососы-пьлеотделители с рециркуляционными циклонами ЦН-15У диаметром 600мм.

Результаты инструментальных измерений показали низкую эффективность работы рециркуляционных циклонов- 20-30\%. Причиной является наличие больших подсосов в месте выгрузки уловленной пыли 9\%. На величину подсосов влияют два фактора:

- наличие неплотностей в шлюзовом питателе, которые можно уменьшить, внедрив мероприятия ранее изложенные.

- выгрузка уловленной пыли из рециркуляционного циклона осуществляется в один шнековый транспортёр с выгрузкой из батарейного циклона, работающего под давлением.

Поэтому рекомендуется устанавливать дополнительный шнековый транспортёр для рециркуляционного циклона и снизить величину подсосов через шлюзовой питатель.

Выполнение данных мероприятий позволяет повысить эффективность очистки в рециркуляционном циклоне дымососа-пылеотделителя до $80 \%$.

Внедрение вместо рециркуляционного циклона ЦН-15У инерционного пылеуловителя на встречных закрученных потоках серии ВИП позволяет повысить эффективность очистки газа на данной ступени на 15-20\%.

Кроме того, предлагается разомкнуть схему и очищенный в пылеуловителе газ не возвращать в дымосос-пылеотделитель, а подать в сушильный барабан, в послетопочное пространство.

Внедрение данной схемы позволяет снизить величину выбросов на 14-16\%; а также сэкономить до $10 \%$ топлива.

В ходе обследования работы асфальтобетонных заводов были проведены замеры запылённости удаляемых от смесителей газов при различной последовательности загрузки компонентов. Результаты замеров показали, что при загрузке компонентов в следующей последовательности: щебень, битум, песок и минеральные добавки концентрация пыли в удаляемом газе на10-15\% меньше, чем при другой последовательности. Это достигается тем, что щебень обволакивается поступающим после него в смеситель битумом и при последующей загрузке песка и минеральных добавок 
основная часть мелкой пыли равномерно прилипает к нему.

Внедрение данного мероприятия позволяет снизить начальную концентрацию пыли, поступающей на очистку от смесителя на 10-12\%.

Многофакельные форсунки серии МФ хорошо зарекомендовали себя в камерах орошения систем кондиционирования воздуха, как надёжные не забивающиеся и эффективно работающие при невысоких давлениях.
Испытания циклона-промывателя СИОТ с установленными в нём тремя форсунками МФ-6 показали рост эффективности очистки газа на $5 \%$.

Разработка наилучших доступных технологий с целью максимального снижения загрязняющих веществ в отходящих газах на основе предложенных мероприятий на примере асфальтобетонный предприятий позволяет достигнуть устойчивого снижения удельных и валовых выбросов предприятия на 15-30\%, осуществить возврат уловленного продукта в производство, и улучшить санитарно-гигиенические условия в рабочих зонах.

\section{ЛИТЕРАТУРА}

1. ГОСТ Р 56828.15-2016 Наилучшие доступные технологии. Термины и определения.

2. Федеральный закон от 10.01.2002 N7-Ф3 «06 охране окружающей среды».

3. ИТС 22-2016«0чистка выбросов вредных (загрязняющих) веществ в атмосферный воздух при производстве продукции (товаров), а также при проведении работ и оказании услуг на крупных предприятиях».

(c) Шкляр Марина Александровна ( marishkl@mail.ru ), Алтынов Константин Сергеевич (altynov_90@mail.ru ), Азаров Артем Викторович ( artazarov@mail.ru ), Жукова Наталья Сергеевна ( pns15@yandex.ru).

Журнал «Современная наука: актуальные проблемы теории и практики»

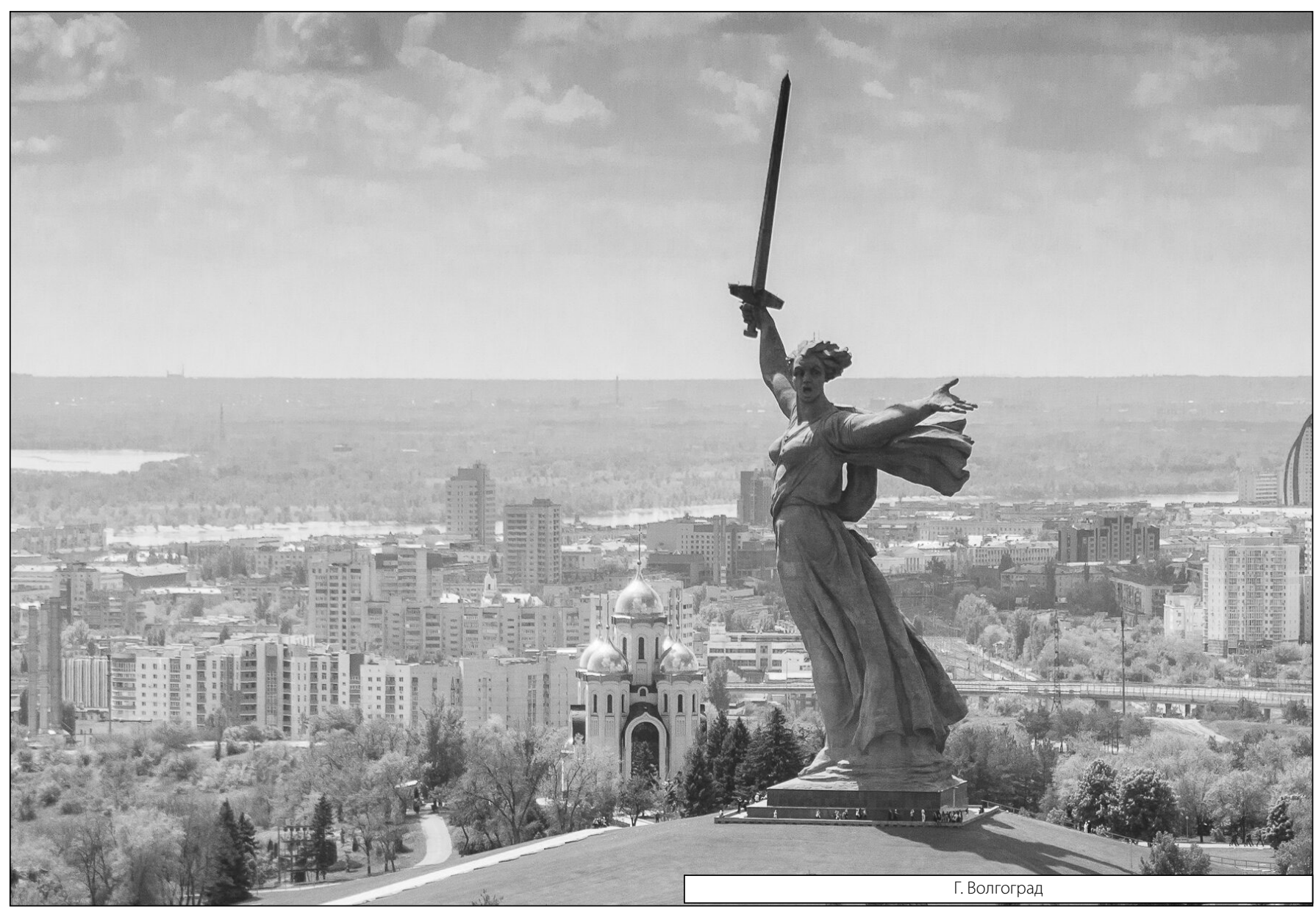

